\title{
DE ALEJANDRÍA A CÓRDOBA: LA MEDICINA SEGÚN IBN RUSHD Y LA TRADICIÓN ARABOISLÁMICA
}

\author{
Miquel Forcada \\ Universidad de Barcelona \\ Email: mforcada@ub.edu \\ ORCID iD: https://orcid.org/0000-0002-9411-6973
}

Recibido: 4 abril 2019; Aceptado: 8 octubre 2019.

Cómo citar este artículo/Citation: Forcada, Miguel (2020) "De Alejandría a Córdoba: la Medicina según Ibn Rushd y la tradición araboislámica", Asclepio, 72(2): p312. https://doi.org/10.3989/asclepio.2020.13

RESUMEN: Ibn Rushd consideró la medicina como un arte productivo en su al-Kulliyyāt fi l-țibb, escrito entre 1162 y 1169 , y como una ciencia en su comentario al poema de Ibn Sīnā sobre la medicina (Sharh Urjūzat Ibn Sinnā fï I-țibb), escrito en 1180. En Kulliyyāt, Ibn Rushd sigue de manera bastante estricta las ideas sobre el estatus de la medicina del filósofo al-Fārābī. En Sharh Urjūzat Ibn Sinnā, Ibn Rushd sintetiza las concepciones de varias obras, entre las cuales Masā'il fi l-țibb de Hunayn ibn Ishāa y Hubaysh, Qānūn fi l-țibb de Ibn Sinā y las obras sobre la lógica aristotélica de al-Fārābī. El análisis conjunto de estas fuentes, más las aportaciones de un nuevo manuscrito de Sharh Urjūzat Ibn Sinnā, proporcionan una idea más clara de la concepción de la medicina expuesta en esta obra y, en consecuencia, podemos reconsiderar y relativizar la diferencia entre esta concepción y la que se expone en Kulliyyāt. Las ideas de Ibn Rushd sobre el estatus de la medicina se analizan de acuerdo con el contexto sociopolítico en que fueron concebidas, considerando especialmente el hecho de que Sharh Urjūza Ibn Sīnā fi l-țibb fue escrito para las elites intelectuales y políticas del régimen almohade.

PALABRAS CLAVE: Ibn Rushd; Ibn Sīnā: al-Fārābī; medicina; filosofía.

\section{FROM ALEXANDRIA TO CÓRDOBA: MEDICINE ACCORDING TO AVERROES AND THE ARABOISLAMIC TRADITION}

ABSTRACT: Ibn Rushd considered medicine as a productive art in his al-Kulliyyāt fi l-țibb, written between 1162 and 1169 , and as a science in his commentary on Ibn Sinnā's poem on the subject (Sharḥ Urjüzat Ibn Sïnā fi l-țibb), written in 1180. In Kulliyyāt, Ibn Rushd followed quite strictly the ideas on the status of medicine propounded by the philosopher al-Fārābī. In Sharh Urjūzat Ibn Sinnā, Ibn Rushd summarised the conceptions of several works including Ḥunayn ibn Isḥāq's Masā'il fil-țibb, Ibn Sīnā's Qānūn fi l-țibb and al-Fārābī's works on Aristotle's logic. The joint analysis of these sources and the evidence provided by a new manuscript of Ibn Rushd's Sharh give us a clearer idea of the conception of medicine extant in this latter work and, in consequence, we can reconsider and relativise the difference between it and the conception expounded in Kulliyyāt. Ibn Rushd's ideas on the status of medicine are analysed according to the sociopolitical context in which they were conceived, taking particular account of the fact that Sharh Urjūza Ibn Sinā fi I-țibb was written for the intellectual and political elites of the Almohad regime.

KEY WORDS: Ibn Rushd; Ibn Sīnā; al-Fārābī; Medicine; Philosophy.

Copyright: ( 2020 CSIC. Este es un artículo de acceso abierto distribuido bajo los términos de la licencia de uso y distribución Creative Commons Reconocimiento 4.0 Internacional (CC BY 4.0) 


\section{INTRODUCCIÓN}

La concepción de medicina que Averroes (Ibn Rushd, m. 1198) expresa en Colliget es distinta a la que expone en una obra posterior, el comentario al poema didáctico sobre medicina de Avicena (Ibn Sinnā, m. 1037), conocido como Cantica Avicennae (Urjūza fi l-țibb). Si en Colliget (Kitāb al-Kulliyyāt fi l-țibb) Ibn Rushd presenta una medicina concebida como arte, en el comentario (Sharḥ Urjūzat Ibn Sinā) la muestra como ciencia (Mc Vaugh, 1990, p. 70, Jacquart, 2013, p. 607). La conceptualización de Kulliyyāt depende casi por completo de al-Fārābī (m. 950) pero la del Sharh es fruto de la síntesis de diversas fuentes que Ibn Rushd combina de modo complejo e incluso irónico. La concepción de la medicina de esta segunda obra no puede ser entendida de modo unívoco ni interpretada sin el análisis conjunto de sus fuentes. Ibn Rushd concentra en el Sharh una parte sustancial de más de doscientos años de especulación de los médicos araboislámicos sobre qué es la medicina, y muchos más siglos de debate si tenemos en cuenta las hondas raíces de la discusión. Uno de los problemas principales de Ibn Rushd y de los autores araboislámicos que abordan el tema es la conocida ambigüedad de sus mayores referentes intelectuales sobre la medicina: tanto Aristóteles como Galeno definen la medicina en diversos tratados como epistēmē y tēkhnē, ciencia y arte y, dentro de la segunda categoría, ambos la califican como productiva y estocástica. ${ }^{1}$ Por otra parte, la naturaleza de la medicina no es solamente una cuestión de epistemología, sino también de historia social de las ideas científicas. La definición de la medicina constituye, como puede verse en Galeno (Vegetti, 1994), una de las más directas cartas de presentación de la disciplina ante la sociedad que la sostiene. De ello son conscientes tanto los médicos araboislámicos como los europeos (Mc Vaugh, 1990, p. 81) y, también, Ibn Rushd. En el contexto sociopolítico y cultural de la corte almohade a la que Ibn Rushd servía, sus ideas sobre la medicina reflejan, por un lado, la compleja relación que las disciplinas racionales mantenían con el poder, y por otro, la voluntad de los médicosfilósofos áulicos de influir en la orientación intelectual de las elites políticas.

\section{LAS DISTINTAS VISIONES DE LA MEDICINA RECOGIDAS POR IBN RUSHD}

\section{1. ḤUNAYN IBN ISḤĀQ (M. 874) Y EL PSEUdogalénico DE SECTIS}

La Urjūza de Ibn Sīnā empieza definiendo la medicina como "conservación de la salud y curación de la enfermedad"; no indica si es ciencia o arte, pero la divide en dos partes: teoría (lit. 'ilm, "ciencia") y práctica ('amal, lit. "trabajo"). ${ }^{2}$ La principal razón para tomar esta definición y división como punto de partida del estudio de Ibn Rushd es que expresan una visión de la medicina ampliamente difundida en los siglos IX y X. Aunque simple, esta definición dual parece desplazar en muchos libros a una de las definiciones más conocidas de Galeno, la que da en Ars medica a partir de Herófilo: "medicina es la ciencia de lo sano, lo insalubre y lo neutro"; es decir, un definición parecida a la fórmula dual que incluye el estado neutro. ${ }^{3}$ En el Canon (al-Qānūn fi l-țibb), Ibn Sinā plantea el asunto de un modo distinto que veremos más adelante. ${ }^{4}$ Se puede, sin embargo, anticipar la causa de esta diferencia siguiendo a Jacquart (Jacquart, 2002 y 2003): la Urjūza no sintetiza la medicina expuesta en el Qānūn, sino la de un texto introductorio como las Masā'il fi l-țibb de Hunayn ibn Ishāa y su sobrino Ḥubaysh (Isagoge loannitti). Esta introducción está basada en buena medida en Ars medica de Galeno y en el pseudo-galénico De Sectis (Jacquart y Palmieri, 1996, Jacquart, 1994). El resumen de esta última obra contenido en los Summaria Alexandrinorum empieza con la división en teoría y práctica y sigue con la subdivisión de las mismas en fisiología, patología, semiótica, por una parte, y en higiene y terapia por otra; Masā'il, empieza del mismo modo. ${ }^{5}$ La bipartición, por lo tanto, no procede del propio Galeno sino de los yatrosofistas alejandrinos tardíos, muchos de ellos maestros de medicina y filosofía a la vez, que veían en esta división una manera de poner de relieve el carácter científico de la medicina (Jacquart, 1998, p. 201), y, en consecuencia, transmitir una percepción de la misma como disciplina elevada semejante a la filosofía. Los comentarios al De Sectis de lohannes Alexandrinus (s. VI) y de Agnellus de Ravenna (fl. ss. VI-VIII) insisten especialmente en esta equiparación. ${ }^{6}$ El origen de la definición bipartita es más complejo y merecería un estudio que no podemos emprender aquí. Sin embargo, podemos avanzar algunas ideas y datos que permitan una mejor comprensión de los textos de Ibn Rushd. Fórmulas similares a "mantenimiento de la salud y curación de la enfermedad" aparecen en algunas obras de Galeno, aunque no como definición de la medicina sino como expresión de los principales objetivos del médico y la medicina (Eijk, Van der, 2005, p. 117-118). En el pseudo-galénico Introductio sive medicus, la fórmula dual aparece como una definición inapropiada de la medicina, ${ }^{7}$ y en otro libro 
atribuido a Galeno, Definitiones Medicae, ${ }^{8}$ como una definición más entre otras. En De Sectis, la fórmula dual figura también como explicación de los objetivos de la medicina, y, una variante de la misma, como definición. ${ }^{9}$ En la traducción de Hunayn, que fue el texto que los médicos árabes leyeron, reza: "dicen los antiguos que la medicina es la ciencia de las cosas relativas a la salud y de las cosas relativas a la enfermedad". ${ }^{10}$ Los comentarios al De Sectis contienen una definición similar, atribuida a Alexander Philaletes y a Sorano. ${ }^{11}$ Parece posible que, debido a la influencia conjunta de De Sectis - junto a sus resúmenes y comentarios- ${ }^{12}$ y Masā'il de Hunayn, los principales manuales médicos araboislámicos incluyeran la bipartición teoría/práctica y una definición de medicina construida sobre la fórmula "conservación de la salud y curación de la enfermedad". Ambos elementos aparecen asociados como una unidad inseparable en los principales manuales de la medicina araboislámica anteriores al Qānūn, insertos en un contexto en el que la medicina se considera sistemáticamente como ciencia y se sitúa en un plano de excelencia similar al de la filosofía. ${ }^{13}$ La calificación de la medicina como ciencia o arte es una cuestión relativa ya que, empezando por el propio Aristóteles, a menudo los autores no distinguen con precisión los límites de ambos conceptos y "arte" puede perfectamente subsumir "ciencia". El significado preciso ha de buscarse en el contexto que, en este caso, está determinado por la voluntad de elevar el estatus de la medicina. Parece, en consecuencia, que en los siglos IX y X, la percepción general del médico y de la medicina en sectores significativos las sociedades araboislámicas está determinada en buena medida por la imagen de la medicina como una disciplina científica tan elevada como la filosofía. Una prueba de ello es el uso por parte de Ibn Sīnā de la definición y la división bipartitas que ponen énfasis en la palabra 'ilm, en un texto como la Urjūza, destinado a promocionar la medicina entre las clases altas de Persia, es decir, entre los potenciales patrocinadores. ${ }^{14}$ Ibn Rushd debe haber sido consciente de la carga simbólica asociada a la presentación de la medicina en la Urjūza.

\subsection{LA MEDICINA SEGÚN AL-FĀRĀBī}

El filósofo al-Fārābī (m. 950), uno de los raros autores de máxima referencia en la filosofía araboislámica medieval que no fue médico, analiza la medicina de forma distinta prescindiendo tanto como le es posible de la noción "ciencia". ${ }^{15}$ Esta postura está determinada por uno de los ejes principales del proyecto intelectual de al-Fārābī: centrar el discurso filosófico en Aristóteles. Una de las principales consecuencias de este planteamiento consiste en la revisión crítica de los autores, especialmente Galeno, que presentan contradicciones con las doctrinas aristotélicas. ${ }^{16} \mathrm{EI}$ discurso de al-Fārābī sobre la medicina presenta dos caras inseparables. Por un lado, la solución de un problema epistemológico legado por Aristóteles, ya que al-Fārābī es un filósofo hondamente interesado por el método científico aristotélico (Endress, 1997) y parece haber aspirado a dar una síntesis harmónica de lo que dice Aristóteles sobre el estatus de la medicina; por otro lado, la crítica de la impostación filosófica, aunque dirigida no tanto a Galeno como a los seguidores araboislámicos de los alejandrinos. El pensamiento farabiano tiene, en este sentido, una importante vertiente ideológica (Zimmermann, 1976, pp. 407-408): el filósofo reclama ante la sociedad su papel de principal director de la investigación científica y educador de las elites. Para ello, tiene que distinguir al filósofo puro del médico-filósofo como alṬabarī que, durante el siglo IX, ha monopolizado la transmisión y la difusión de la filosofía, especialmente la lógica, y proclamar la primacía del primero sobre el segundo, de Aristóteles sobre Galeno, de la filosofía sobre la medicina. Las referencias a la medicina en la obra de al-Fārābī son abundantes, y generalmente transmiten la idea de que es un arte y no una ciencia teórica y deductiva similar a las matemáticas. En los epítomes de Dialéctica y Retórica de Aristóteles (Kitāb al-Jadal y Kitāb al-Khitāba, respectivamente, ${ }^{17}$ alFārābī considera que la medicina, al igual que la navegación, es un arte estocástico o conjetural, que, en contraposición a las ciencias deductivas, no garantiza la consecución de un resultado. En este tipo de disciplinas, el artífice no utiliza el razonamiento deductivo propio de las ciencias teóricas sino la deliberación (rawiyya), que es un tipo de razonamiento basado en la opinión -y, por lo tanto, inadecuado para las ciencias-, cuya finalidad consiste en determinar los medios por los cuales se conseguirá un fin en el contexto de una situación complicada e incierta (las circunstancias de un viajero en una tormenta, o de un paciente en una enfermedad). La definición de medicina más conocida se halla en unos comentarios críticos a Galeno sobre filosofía natural centrados en anatomía y fisiología. ${ }^{18}$ Al-Fārābī califica a la medicina de "arte productivo" (șinā'a fā 'ila), ${ }^{19}$ como hacen Aristó- 
teles y Galeno en alguna ocasión. Concretamente, para al-Fārābī, es un "arte productivo basado en principios verdaderos con cuyas acciones se pretende conseguir la salud del cuerpo humano y de sus órganos." ${ }^{20}$ Como tal arte productivo, la medicina se divide en: conocimiento del substrato, el cuerpo humano; los fines, restablecimiento y conservación de la salud; y las acciones y los instrumentos necesarios para alcanzar un fin. Después divide la medicina en otras siete partes. ${ }^{21}$ El filósofo natural investiga en el cuerpo humano y en la salud y la enfermedad con el fin de alcanzar el conocimiento puro, 22 que le conducirá a la felicidad y la perfección. El médico conoce en la medida necesaria para cumplir su fin..$^{23}$ Frente a la nobleza de la ciencia y el científico, la medicina y el médico son presentados por al-Fārābī como un arte y un artesano, respectivamente, y al-Fārābī insiste en ello comparando al médico con el carpintero y otros artífices y a la medicina con los correspondientes oficios. ${ }^{24}$

Radd 'alā Jālīnūs describe, aunque no desarrolle la cuestión, una disciplina teórico-práctica. En este sentido, lo que dice en esta obra debe ser complementado con otra línea de análisis que al-Fārābī expone en su epítome de Analíticos Posteriores de Aristóteles, Kitāb al-Burhān. La medicina se estudia aquí en el seno de una sección cuyo principal objetivo es la distinción entre tres clases de ciencias y artes: teóricas, prácticas, y compuestas de teoría y práctica. La medicina es un arte del tercer tipo (șinā'a 'ilmiyya wa-'amaliyya); como arte compuesta, es una disciplina a la que la experiencia no le basta para para alcanzar sus fines y necesitará ser complementada con teoría. ${ }^{25}$ Está teoría tendrá dos fuentes: por un lado, la teoría externa, que es la proporcionada por las ciencias teóricas puras, esencialmente la filosofía natural; por otro, la teoría propia, que consiste en la capacidad del médico de teorizar sobre los mismos objetos de conocimiento que la filosofía natural, pero, como hemos visto más arriba, sólo según el fin que le es propio y en la medida suficiente para cumplir dicho fin. ${ }^{26}$ Lo que no deja claro al-Fārābī es el alcance de la capacidad de teorizar de la medicina, porque lo que dice explícitamente es que el conocimiento generado por la experiencia médica debe ser aprovechado por la filosofía natural en forma de premisas que permitan obtener verdadera ciencia. ${ }^{27}$ Sin embargo, el concepto de ciencia es relativo en Aristóteles: una cosa es lo que dice sobre el método científico y otra es su práctica de la ciencia, especialmente en los tratados sobre biología, donde es mucho menos ri- guroso y admite premisas que no pueden ser consideradas, en sentido estricto, conocimiento universal. ${ }^{28} \mathrm{Al}$-Fārābī cita explícitamente esta circunstancia. ${ }^{29}$ Además, al-Fārābī entiende el trabajo del científico como un proceso gradual en el que el resultado final, la certeza sobre algún asunto, es relativo, y por lo tanto, el resultado de demostraciones no apodícticas puede ser considerado, provisionalmente, como ciencia. ${ }^{30}$ Podemos suponer, por lo tanto, que una parte del conocimiento que el médico genere en el curso de su praxis puede ser sometido a un cierto proceso de abstracción que permita considerarlo como ciencia, aunque no ciencia apodíctica.

La exposición más clara que al-Fārābī efectúa sobre la medicina entendida como teoría y práctica aparece en un tratado sobre política, religión y ética, $K$. alMilla, en el cual habla del método de la medicina comparándolo con la política. Al-Fārābī describe minuciosamente el tratamiento de la ictericia, ${ }^{31}$ que empieza en tres premisas generales ordenadas en grado descendente de abstracción (la curación por el contrario, la fiebre se combate mediante el frío y el agua de cebada cura la ictericia). Al-Fārābī prosigue mediante una minuciosa descripción de la aplicación de estos principios al paciente concreto, que constituye un excelente ejemplo de aplicación del razonamiento deliberativo (Galston, 1990, pp. 111-112), en el cual la deducción es secundaria. Seguidamente, al-Fārābī ofrece la descripción del "médico perfecto", al-țabīb al-kāmil: ${ }^{32}$

Es evidente que su capacidad [la del médico para determinar un tratamiento destinado a un enfermo concreto] no le ha sido proporcionada por los libros de medicina en que ha aprendido y con los que se ha ejercitado, ni por su capacidad de conocer los universales (kulliyyāt) y los elementos generales establecidos en los libros de medicina, sino por la facultad que aparece mediante la realización repetida de las prácticas de la medicina (muzāwalat a 'māl al-țibb) en cada uno de muchos cuerpos, en la prolongada observación de los estados de los enfermos, en la experiencia que se alcanza tras mucho tiempo dedicado a la curación y a cuidar de cada individuo. En consecuencia, el médico perfecto es aquel cuya profesión se completa, hasta el punto de que es capaz de llevar a cabo las acciones posibles en esta profesión, mediante dos facultades: la capacidad de conocer los universales que constituyen las distintas partes de su arte de modo absoluto y sin que nada se le escape y la facultad que aparece en él mediante la prolon- 
gada realización de las acciones de su arte (țūl af'āl șinā'āti-hi) en cada individuo.

Una de las fuentes principales de este pasaje es Ética Nicomaquea de Aristóteles (1139a3-15), donde se divide el alma racional en dos partes, la facultad científica que permite entender lo universal, y la facultad razonadora o deliberativa que permite tratar con lo variable. Como vemos en $K$. al-Milla, el ámbito natural del médico es el segundo. La teoría se aprende especialmente en los libros pero la capacitación para la práctica nace de la práctica, de la experiencia real. Ello no significa, sin embargo, que una parte del conocimiento nacido de la experiencia proporcionada por la práctica no pueda ser susceptible de ser objeto de algún tipo de teorización, como demuestra el hecho de que Ibn Rushd hable de principios universales o generales (kulliyyāt) referidos tanto a la teoría como a la práctica de la medicina, e Ibn Sīnā se refiera a la "teoría de la práctica".

\subsection{LA MEdICINA SEgÚN IBN SīNĀ}

Ibn Sīnā conoció bien la obra de al-Fārābī, que, en cierto modo, continuó. Compartía muchas de las doctrinas y opiniones de al-Fārābī y, entre ellas, la superioridad del filósofo sobre el médico. Sin embargo, presenta en el Qānūn una postura intermedia entre la de Hunayn y la de al-Fārābī basada en la fórmula dual de constante referencia: ${ }^{33}$

La medicina es una ciencia en la cual se conocen los estados del cuerpo humano en tanto que está sano o deja de estarlo, para preservar la salud que se ha alcanzado o devolverla cuando se ha perdido.

Por lo tanto, Ibn Sīnā concibe la medicina como una disciplina unitaria a la que llama "ciencia", 'ilm. ${ }^{34}$ La divide entre un "conocimiento teórico" ('ilm 'ilmī; lit. "ciencia científica") y una "teoría de la práctica" ('ilm 'amalī, lit. "ciencia práctica") (Gutas, 2003, pp. 151154). La parte teórica consiste en el conocimiento de los fundamentos de la medicina en aquello cuyo aprendizaje "es útil para [formar] una convicción (ítiqād) y no interviene en la explicación de la naturaleza (kayfiyya) de la práctica". "Es interesante resaltar el hecho de que la palabra "convicción" no va seguida en el Qānūn del adjetivo "cierta" (ítiqād yaqīnì), que sí la acompaña para definir los fines de la filosofía teórica (matemática, filosofía natural, y metafísica) en una de las obras más conocidas de Ibn Sinnā sobre clasificación de las ciencias. ${ }^{36}$ Para Ibn Sīnā, la medicina no alcanza, ni en su parte puramente teórica, un conocimiento cierto sino simplemente una opinión cualificada (Mc Ginnis, 2010, p. 233); es decir, la medicina se mantiene en los límites de una disciplina conjetural. En este sentido, Ibn Sīnā subordina el médico al filósofo concluyendo que el médico se equivocará si intenta definir los elementos y las complexiones a partir de su ciencia y no de la del filósofo. ${ }^{37}$ La práctica consiste en aquella parte de la ciencia médica cuyo aprendizaje proporciona una opinión ( $\mathrm{ray}^{\prime}$ ) "relacionada con la explicación de la naturaleza (kayfiyya) de la práctica"; 38 es decir, un conocimiento que nos permite deducir un tratamiento que no tendrá ninguna garantía de seguridad ya que, como Ibn Sinnā dice, la causa de la enfermedad puede ser distinta que la que se ha pensado en un principio. Ibn Sīnā plantea, pues, una medicina muy similar a la que define al-Fārābī, es decir, una disciplina teórico-práctica (Mc Ginnis, 2010, p. 230), y deliberativa, a la cual se le puede aplicar el término "ciencia" por extensión, dentro de los límites de flexibilidad admitidos por al-Fārābī. La diferencia más importante con al-Fārābī se halla en la práctica, ya que, en realidad, Ibn Sīnā excluye la práctica efectiva de la introducción del Qānūn: la práctica no tiene que ver con trabajo físico, ni es práctica en acto; ${ }^{39}$ el estudiante que aprende las dos partes de la medicina alcanzará un conocimiento de ambas "a pesar de no haber realizado nunca una práctica". ${ }^{40}$ La práctica, en definitiva, es algo que puede aprenderse como la teoría, ${ }^{41}$ y sólo en el caso del aprendizaje de la anatomía se menciona la percepción mediante los sentidos y la disección. ${ }^{42}$ Ibn Sīnā nos presenta dos paradojas interesantes conectadas entre sí: como filósofo y científico, es empírico (Mc Ginnis, 2003; Gutas, 2012), pero, como médico, es teórico y reticente a hablar de la práctica (Pormann, 2013; Álvarez Millán, 2010); no cree que la medicina sea una ciencia apodíctica, pero la presenta como ciencia. La explicación de estas paradojas requiere un estudio que excede los límites del presente, pero podemos considerar, entre las hipótesis posibles que explicarían la segunda paradoja, la intención de prestigiar una disciplina que es el oficio que le permite ganarse la vida y acceder a las altas esferas.

\section{IBN RUSHD Y LA MEDICINA}

\subsection{KITĀB AL-KULLIYYĀT}

Las ideas de al-Fārābī sobre la aristotelización de la filosofía y la ciencia son seguidas en al-Andalus, don- 
de Ibn Bājja (Avempace, m. 1139), las convierte en uno de los ejes principales de su obra y las transmite a la posteridad; en cierto modo, todos los grandes médicos-filósofos andalusíes del siglo XII son discípulos indirectos suyos. La concepción farabiana de la medicina aparece ya reflejada en la obra médica de Ibn Bājja (Forcada, 2011b), y luego la recogen Maimónides (m. 1204) (Bar-Shela y Hoff, 1963, Stroumsa, 2009, pp. 135-138) y, sobre todo, Ibn Rushd. Kulliyyāt pertenece a una etapa relativamente temprana de la obra de Ibn Rushd, ya que la escribió entre 1162 y 1169 (Álvarez de Morales y Vázquez de Benito 2001, 96-97 y 103 ss.), especialmente marcada por la influencia de la lógica de al-Fārābī y por lo tanto, de sus ideas sobre epistemología científica. ${ }^{43} \mathrm{lbn}$ Rushd no sólo reproduce en Kulliyyāt, sin explicitarlo, la definición de la medicina que al-Fārābī da en Radd 'alā Jālīnūs, sino que estructura el libro de acuerdo con las siete divisiones de la medicina de al-Fārābī (Gätje, 1986). Podemos considerar, en consecuencia, que Ibn Rushd materializa el proyecto de manual médico que al-Fārābī esboza en estas obras, estructurado alrededor de la idea de la medicina como arte productivo, y, a la vez, como arte estocástico: la medicina es un arte que debe producir salud, pero, al igual que la navegación y la dirección de un ejército, no puede garantizar el resultado final; en los procesos que sigue para conseguir los fines, utiliza la deliberación pero no la demostración. ${ }^{44}$ En realidad, la deuda de Ibn Rushd hacia al-Fārābī es más profunda porque el proyecto completo expresado en $K$. al-Kulliyyāt, es decir, un manual sobre cuestiones generales más un manual sobre cuestiones particulares basado en la experiencia médica, ${ }^{45}$ nace del retrato del "médico perfecto" de al-Fārābī.

\subsection{SHARH URJŪZAT IBN SĪNĀ}

\subsubsection{Los textos y los subtextos}

Los pasajes más relevantes del Sharh sobre la naturaleza de la medicina aparecen en los comentarios a los versos 17 y 18 de la Urjūza de Ibn Sinnā y conviene releerlos a la luz de sus fuentes: ${ }^{46}$

17. La medicina es conservación de la salud y curación de la enfermedad//

Que aparece en el cuerpo por una causa

1. Sus palabras "conservación de la salud y curación de la enfermedad" constituyen una definición que estaría completa si dijéramos que la medicina es un arte cuya obra ${ }^{47}$ es la conservación de la salud y eliminación de la enfermedad a partir de la ciencia y la experiencia (...) He dicho en la definición "a partir de la ciencia y la experiencia" porque no es suficiente en este arte la ciencia sin la experiencia ni la experiencia sin ciencia, sino que ambas son necesarias. ${ }^{48}$

2. Galeno definió este arte como conocimiento de las cosas relacionadas y conectadas con la salud, la enfermedad y el estado en el que no se suceden ni la salud ni la enfermedad (...) Puede parecer que esta definición carece de la diferencia ${ }^{49}$ que permite distinguir entre este arte y la parte del arte de la naturaleza que estudia la salud y la enfermedad. El arte de la medicina enseña la salud, la enfermedad, sus causas y sus signos para preservar la salud y eliminar la enfermedad. Por esto, [la medicina sólo] alcanza, del conocimiento de la salud y la enfermedad, la proporción que es útil para la práctica. En cuanto a la filosofía natural, su propósito respecto al conocimiento de la salud y la enfermedad es el mero conocimiento. Por esto, el filósofo natural debe alcanzar, del conocimiento de ambas, quiero decir, de la salud y la enfermedad, el máximo [conocimiento] sobre las naturalezas de ambas que puede alcanzar un ser humano. ${ }^{50}($...)

18. He distribuido la primera en ciencia y práctica// y la ciencia en tres se completa.

1. Quiere decir que la medicina se divide primeramente en dos grandes partes, una, llamada ciencia ('ilm), y la otra práctica ('amal). Y su afirmación "y la ciencia en tres se completa" significa que la parte de la ciencia alcanza la perfección con tres secciones que posteriormente [Avicena] menciona. ${ }^{51}$ Sin embargo, ésta no sería una división real del arte de la medicina $<$ ni estaría plenamente de acuerdo con lo que Galeno dice $>.^{52}$ Galeno dijo en su definición que [la medicina] es el conocimiento de la salud y la enfermedad, las cosas relacionadas con ambas y el estado que no es ni salud ni enfermedad. Si ello es así, las partes de la medicina sólo serán ciencias, no ciencias y práctica.

2. < Y ello [la división en ciencia y práctica] tampoco es correcto porque no se sigue de que las artes sean científicas el hecho de que no sean prácticas. Las dos partes de la medicina corresponderían a un arte científico basado en el pensamiento y la deliberación $>.{ }^{53}$ Esto es así porque, entre las artes que se denominan "prácticas", hay algunas que se consideran de este modo porque se aprenden con la práctica, como por ejemplo la carpintería o la sastrería, y hay otras a las que se denomina "cientificas" porque se aprenden 
mediante la ciencia, quiero decir, mediante las demostraciones y las definiciones, aunque la finalidad de la ciencia en ellas sea la práctica. ${ }^{54}$ Esta es la situación del arte de la medicina, porque no puede descartarse que haya artes que se aprendan de las dos maneras conjuntamente, <mediante la ciencia y la práctica $>,{ }^{55}$ si aceptamos que estas artes son únicas. Puede pensarse que el arte de la medicina es de esta manera porque la parte [de la medicina] en la cual se opera con las manos ${ }^{56}$ se aprende en mayor medida mediante la práctica y la imitación. ${ }^{57}$

3. La justificación de esta división [en teoría y práctica] es que, dado que la ciencia en el arte de la medicina se divide en dos ciencias ${ }^{58}$ - una de la que participa el filósofo natural $<y$ otra muy lejana a este último $>{ }^{59}$, y quiero decir que se teoriza [en medicina] sobre las dos ciencias a la vez, ${ }^{60}$ que son [por un lado] la ciencia en que se examina la salud, sus causas y signos, y la enfermedad, sus causas y signos, y [por otro lado] la <segunda> ${ }^{61}$ ciencia, aquella mediante la cual se singulariza el arte de la medicina y que consiste en teorizar sobre cómo y mediante qué se conserva la salud y cómo y mediante qué se elimina la enfermedad -, se denomina, a la parte de la ciencia que comparte la medicina con la filosofía natural, "científica", $62<y$ ya he mencionado a filosofía natural como "científica" $>,{ }^{63}$ y quiero decir por ciencia aquello cuya finalidad predeterminada es solamente el conocimiento teórico ${ }^{64}$ y no la práctica; ${ }^{65}$ y se denomina a la otra parte, aquella por cuyo teorizar se singulariza el arte de la medicina, "práctica", ${ }^{66}$ ya que está cercana a la práctica y, de forma particular y frecuente, se consigue la excelencia en su acción mediante la imitación (ihtidhā'), esto es, mediante la práctica. Por esta razón una de las condiciones del médico es que, además de basarse en la ciencia médica, realice repetidamente las acciones de la medicina (muzāwilan li-a'māli-hi). La cirugía es, como dijimos, específicamente práctica y no se puede aprender mediante la palabra (bi-l-qawl) excepto en una pequeña parte, ${ }^{67}$ y <parece ser que lo mismo se aplica a la anatomía, y quiero decir que no se puede llegar a conceptualizarla bien mediante la palabra (bi-l-qawl) excepto en una pequeña parte $>.{ }^{68}$

4. El primero que dividió la ciencia médica de esta manera fue Ḥunayn ibn Isḥāq al-Mutațabbib, quien fue replicado por Ibn Rị̣wān, que pretendía que los libros originales de Galeno sobre medicina indican que esta división es errónea. Le venció Abū I-'Alā' Zuhr sosteniendo que esta división salía en algunos libros atribuidos a Galeno aunque la verdad sobre este asunto es la que yo explico.

La síntesis de estos textos puede empezar por el final, ya que, en v. 18§4, Ibn Rushd enseña posibles fuentes, indicando el origen de la división en teoría y práctica en Hunayn y mencionando que el debate de fondo estaba vivo en al-Andalus. Había enfrentado a distancia a un médico como Abū l-'Alā' Zuhr ( $\mathrm{m}$. 1131, padre de Abū Marwān Ibn Zuhr), eminentemente empírico (Álvarez Millán, 2010), con un médico-filosófo egipcio, Ibn Rị̣wān (m. 1061 ó 1068), seguidor de al-Fārābī (Forcada, 2019). Abū l-'Alā' escribió un libro hoy perdido, que debe ser la obra aludida por Ibn Rushd, cuyo largo título parece un resumen de su contenido: "libro de la aclaración de los testimonios de la difamación sobre la refutación de Ibn Riḍwān referente a la refutación de este último a Ḥunayn ibn Isḥāq sobre su Libro de la introducción a la medicina". ${ }^{69}$ La obra de Ibn Riḍwān refutada tampoco ha llegado a nosotros. ${ }^{70}$ Por los comentarios de Ibn Rushd, parece que el andalusí defendió la división bipartita frente a otra división procedente de Galeno. Cabe la posibilidad de que Ibn Rushd refleje ambas obras pero es imposible saberlo. El conocido comentario de Ibn Rị̣wān de Ars Medica, sin embargo, puede haber sido tenido en consideración por parte de Ibn Rushd, aunque, dado que no tenemos el texto árabe, es difícil trazar paralelismos textuales que lo confirmen. Al principio del comentario, ${ }^{71} \mathrm{Ibn}$ Ridwān plantea cuestiones afines a las que trata Ibn Rushd pero son relativamente generales y pueden proceder del fondo común de lecturas filosóficas: la medicina subordinada a la física natural al igual que otras disciplinas empírico-prácticas como la agricultura y la veterinaria; las opiniones opuestas de Galeno y Aristóteles sobre el estado neutro, que Ibn Rushd rechaza e Ibn Riḍwān acepta con matices (Ottosson, 1984, pp. 168-9 y Van der Lugt, 2011, pp. 18-19). ${ }^{72}$ Existe, sin embargo, una coincidencia que no parece casual. Ibn Riḍwān analiza la definición tripartita de Galeno en función de los requerimientos de la lógica de Aristóteles y Porfirio, es decir, estableciendo género y diferencia: el género de la medicina es el de las ciencias; la diferencia, el estudio de la salud, la enfermedad y el estado neutro. ${ }^{73}$ Ibn Rushd parece criticar este análisis en v.17§2 cuando dice que a la definición de Galeno le falta la diferencia que distinga la medicina de la filosofía natural.

La probable influencia de Ibn Riḍwān no deja de ser secundaria. Las verdaderas fuentes son las que 
Ibn Rushd se calla, Ibn Sīnā y, muy especialmente, al-Fārābī. Éste último aparece enseguida, cuando Ibn Rushd reformula la definición bipartita y la transforma en una versión de la definición de Radd 'alā Jālīnūs y Kullīyyāt: la medicina como arte productivo (v.17§1), definida mediante un género y una diferencia que la distingue de la filosofía natural, y acompañada de la mención de su carácter empírico. Le sigue una demarcación de las áreas de competencia del médico y el filósofo natural según el fin de acuerdo con Radd 'alā Jālīnūs y Burhān de al-Fārābī. En buena medida, el comentario del verso 17 recapitula los argumentos de al-Fārābì en Radd 'alā Jālīnūs, repetidos en Kullīyyāt. En el comentario del v. 18, Ibn Rushd presenta una concepción unitaria de la medicina parecida a la del Qānūn de Ibn Sīnā aduciendo, en cambio, la definición de Galeno. Antes la ha criticado por imprecisa pero ahora la cita reconociendo que transmite la unidad de la medicina, seguramente con la intención de ocultar a Ibn Sīnā. El largo comentario subsiguiente, consiste, por lo tanto, en una suma de matizaciones a Galeno e Ibn Sinnā, que empieza después de la afirmación de que la medicina es ciencia en v.18§1: en v. $18 \S 2$, Ibn Rushd dice que, en realidad, la medicina es, por un lado, un arte estocástico que no se desarrolla mediante la deducción y la demostración apodíctica sino mediante el "pensamiento", es decir, cualquier actividad racional, y la "deliberación", es decir, la opinión; por otro, un arte compuesto de teoría y práctica. En v. $18 \S 3$, se expone que la teoría y la práctica son "ciencias", mostrando de forma difuminada la bipartición inherente a la definición del Qānūn, el 'ilm 'ilmī y el 'amal 'ilmī. Sin embargo, se interpretan siguiendo la argumentación del $K$. alBurhān de al-Fārābī que ya ha precedido en v. $18 \S 2$ y en la que se insiste en esta sección: la medicina es, finalmente, una disciplina teórico-práctica en la cual la teoría se halla al servicio de la práctica y la práctica es, fundamentalmente, la experiencia que capacita al médico. A pesar de la identificación de la medicina con la ciencia, Ibn Rushd califica repetidamente a la primera de arte, poniendo de relieve que su aprendizaje ha de ser el mismo de las artes según al-Fārābī: la imitación del maestro, la práctica repetida, y, en menor medida, la palabra, es decir, la explicación directa del maestro. Si a esto unimos las alusiones a la cirugía, que la introducción del Qānūn y al-Fārābī omiten por completo, está claro que el concepto de medicina y del médico que se transmite es esencialmente empírico y práctico. Lo único que falta en el conjunto del comentario es la noción de que "ciencia" puede tener un sentido relativo. Veamos la posible razón.

\subsection{El texto en el contexto de la corte ALMOHADE}

El poema de Ibn Sīnā llegó a al-Andalus hacia mediados del siglo XII. El primer testimonio relativamente seguro es un comentario de Abū Marwān Ibn Zuhr que alaba su condición de síntesis completa de la medicina (Forcada, 2018, p. 170). En esta época, tanto Ibn Zuhr como Ibn Rushd servían a la dinastía almohade, que dominó al-Andalus y el Magrib durante la segunda mitad del siglo XII y las primeras décadas del XIII. Su régimen político trajo un mensaje religioso renovador caracterizado por una interpretación racionalista del islam, que permitió que los filósofos adquirieran una posición de cierta influencia en la corte, que promovió el saber científico-filosófico. Es probable, además, que médicos-filósofos como Ibn Rushd e Ibn Țuayl fueran miembros de unos cuerpos específicos fundados por el régimen para promover y difundir el nuevo credo. ${ }^{74}$ A la vez, Ibn Rushd e Ibn Țufayl formaban parte de un servicio específico de médicos, que lideraron sucesivamente. En el mismo, aparece un núcleo relativamente amplio de médicosfilósofos, algunos de los cuales fueron discípulos de Ibn Rushd (Forcada, 2011a, pp. 309-310). En un contexto de profunda reforma religiosa e intelectual, los almohades necesitaban educar a las nuevas elites político-religiosas y promovieron la elaboración de obras enciclopédicas y didácticas, destinadas a "educar a los educadores" (Fierro 2009, pp. 100-103, Fierro, 2014, pp. 29-32). Dentro de esta iniciativa pueden enmarcarse diversas obras relacionadas con la ciencia y la filosofía, incluyendo una producción importante de poesía didáctica sobre diversos temas $y$, entre ellos, las ciencias (Forcada 2018, pp. 170-172). El califa Abū Ya'qūb Yūsuf (r. 1163-1184) promovió, instigado por Ibn Ṭufayl, el comentario sistemático de Aristóteles por parte de Ibn Rushd y también estaba hondamente interesado por la medicina: se dice que llegó a saberse de memoria amplios fragmentos de la parte teórica del Kāmil de al-Mājūsī. ${ }^{75}$ Ibn Rushd escribió el Sharh al final de su reinado, ya que según uno de sus manuscritos lo terminó en el 10 de ramadán del 575 (8 de febrero de 1180) (al-'Alawī, 1986, p. 99). En el prólogo, Ibn Rushd nos dice que el comentario fue el resultado de un encargo directo de la corte almohade, aunque sugerido por el mismo lbn 
Rushd mediante un elogio del poema médico de Ibn Sīnā en términos parecidos a los de Ibn Zuhr. ${ }^{76} \mathrm{La}$ razón del encargo, según Ibn Rushd, fue, además de aclarar los conceptos que las exigencias del metro y la rima pudieran haber oscurecido, "dar prestigio al saber y contribuir al bien común", es decir difundir el conocimiento médico-científico entre las elites. El elogio se produjo en una reunión de cortesanos almohades presidida por Abū I-Rabī' Sulaymān ibn 'Abd al-Mu'min (m. 604/1207), un miembro de la más alta nobleza almohade ya que ostentaba el título de sayyid, que distinguía a los miembros de la descendencia del primer califa almohade, 'Abd al-Mu'min. Fue un notable literato de su tiempo (Haremska, 2009) que encarna como pocos la figura del noble almohade interesado por todas las manifestaciones de la alta cultura. Hay que tener en cuenta, además, que su secretario en el momento del encargo era otro importante literato, Ibn 'Abd Rabbihi al-Hafíd (m. 1205) que trató a Ibn Rushd y poseía conocimientos científicos y filosóficos además de literarios (Puerta Vílchez y Rodríguez Figueroa, 2009). Como muestra su nombre, era descendiente de una familia que, en el siglo $X$ se había dedicado a difundir la medicina entre los cortesanos omeyas (Forcada, 2018, 169), también mediante la poesía didáctica. El momento del encargo coincide con una época especialmente importante en la vida de Ibn Rushd: alrededor del 1180, es nombrado juez de Córdoba, comienza la redacción de una de sus obras más importantes, Tahāfut al-Tahāfut que, como es bien sabido, es una obra que defiende el racionalismo, y se convierte en médico personal del califa sustituyendo a Ibn Țufayl (1182). Estamos, pues, ante un Ibn Rushd situado en la cima de su capacidad de influencia política e intelectual y el prólogo del Sharh constituye, en este sentido, un intere- sante documento de su papel de prescriptor intelectual en la corte. En Kulliyyāt, un libro probablemente destinado a convertirse en un manual de los futuros médicos de los almohades, y posiblemente escrito para oponerse a la influencia del Qānūn (Arnaldez e Iskandar, 1975), Ibn Rushd presenta el concepto de medicina que mejor concuerda con el pensamiento de al-Fārābī, su principal maestro en lógica y epistemología. La medicina entendida como "arte productivo" comporta la comparación directa del médico con el artesano. Sin embargo, en una obra destinada a un público mucho más amplio e influyente, que reconoce a Ibn Rushd más como experto en ciencias religiosas y médico que filósofo, parece lógico suponer que el autor se aproveche de Ḥunayn e Ibn Sinnā para presentar la medicina con unos descriptores más positivos en términos simbólicos que transmitan la idea que el médico es un sabio de máximo nivel. En realidad, ni la corte almohade ni ninguna otra reservan un espacio para el filósofo y, por lo tanto, el espacio destinado al médico, que sí existe, debería ser el ámbito del médico-filósofo, o, mejor dicho en este caso concreto, del filósofo-médico. El rigor intelectual de Ibn Rushd le impide abandonar la posición que él considera correcta: la medicina es una disciplina eminentemente empírica, compuesta de teoría y prácti$\mathrm{ca}$, aunque mucho más de lo segundo que de lo primero y, por lo tanto, es más un arte que una ciencia. "La verdad sobre este asunto es la que yo explico" termina diciendo Ibn Rushd y, en el resto del comentario intenta presentar esta verdad a los ojos de las elites magrebíes afirmando, como en Kulliyyāt, la superioridad de Aristóteles sobre Galeno y, mucho más que en Kulliyyāt, su propia autoridad frente a la de Ibn Sīnā.

\section{NOTAS}

1 Sobre esta cuestión, cf. entre distintas referencias posibles: para Aristóteles, Gracia, 1978 y Polansky, 2000; para Galeno, Fortuna, 1987, Boudon-Millot, 2003 y Hankinson, 2004.

2 Ibn Sīnā, Urjūza fi l-țibb, 92, vs. 25-26.

3 Galeno, Ars Medica, I 307 K.

4 Para una comparación entre ambas obras cf. Jacquart, 2003, esp. pp. 273-275 sobre la definición.

5 Autor desconocido, Jawāmi' al-Iskandarāniyyin (Jawāmi Jālīnūs fi Firaq al-Tịbb), 4; Hunayn, Masā'il fi l-țibb, 1; cf. pseudo-Galeno, Definitiones medicae, XIX 351-352 K.

6 Especialmente significativo es el tópico de la medicina y la filosofia como "hermanas"; Iohannes Alexandrinus, Commentaria in librum De sectis Galeni, 14-15 y 23; Agnellus de Ravenna, Lectures on Galen De Sectis, 22.

7 Pseudo-Galeno, Introductio sive medicus, 12:21-13-1; la editora relaciona esta definición con Sorano (Petit, 2009, p. 125).

8 Peudo-Galeno, Definitiones medicae, XIX $351 \mathrm{~K}$.

9 Pseudo-Galeno, De Sectis, I $64 \mathrm{~K}$.

10 Ḥunayn, Kitāb Jālīnūs fi firaq al-țibb li-l-muta'llimīn, 12. 
11 Iohannes Alexandrinus, Commentaria, 14; cf. Temkin 1935, 419.

12 Cf. Pormann, 2003 y 2004, Garofalo, 2007, sobre el De Sectis y las versiones que circularon entre los árabes; Overwien, 2015 analiza pormenorizadamente la influencia del De Sectis en una de las introducciones a la medicina más importantes, Miftāh al-țibb de Ibn Hindū (m. 1029) y ofrece muchas novedades interesantes: debieron circular en árabe comentarios del De Sectis que desconocemos.

13 Al-Ṭabarī (m. ca. 864), Firdaws al-Hikma, 4-6; el autor que más empeño pone en dar una imagen elevada de la medicina como disciplina filosófica; al-Rāzī (m. 925), alManșūrī fï l-țibb, 17-19 y 29, y Mudkhal ilā șinā'at al-țibb, 5; al-Zahrāwī (m. ca. 1013), al-Tașrīf li-man 'ajiza an alta'līf, vol. 1, 2:4 y 4:9-12; al-Mājūsī (m. 982 ó 994), Kāmil fi șina'at al-țibb, vol. 1, 3-15. En el Kāmil la definición principal es la tripartita de Galeno (1, 10 i.f.- 11:1), aunque el autor da otra parecida a la definición bipartita, sin atribución de autor $(1,11: 6)$ : "la medicina es el arte que proporciona la salud"; además, aparece repetidamente la fórmula "mantenimiento de la salud y curación de la enfermedad" (1, 3:14-15, 5:4, 6:9-10). Isaac Israelí (m. ca. 932) da una variante de la definición dual en su tratado sobre las fiebres diciendo que procede de la "filosofía", pero no incluye la bipartición (Ferre 2015, 114).

14 Ibn Sīnā, Urjūza, 89. Ibn Sīnā explica que el poema está escrito para un ministro al cual el autor recuerda que, en el pasado, los sabios realizaban este tipo de obras para reyes y notables. Ibn Sinnā se lamenta de la falta de interés por la medicina en cenáculos cultos, medersas e incluso hospitales; de hecho, según el autor, se han apoderado de la medicina personas sin la más mínima formación.

15 Sobre la medicina según al-Fārābī, cf. las síntesis de Strohmaier, 1998, pp. 165-7 y Chandelier, 2010, y el estudio monográfico de Forcada, 2020. De este último se extractan las nociones necesarias para la contextualización de las opiniones de Ibn Rusdh.

16 Sobre las críticas de al-Fārābī a Galeno, en distintos temas y aspectos, cf. Bürgel, 1967, pp. 286-290, Zimmermann, 1976, Zimmermann, 1981, introd. pp. Ixxxi-Ixxxiii, RichterBernburg, 2008, Karimullah, 2017, El-Fekkak, 2018.

17 Al-Fārābī, Kitāb al-Khițāba, 57-58; Kitāb al-Jadal, 42; cf. Zimmermann, 1976, p. 413, n. 62.

18 Al-Fārābī, Risāla fï l-Radd 'alā Jālīnūs fi mā nāqā ḍa fï-hi Arisțūțalīs li-a 'ḍā' al-insān; es un conjunto complejo de tratados cuya descripción detallada no puede ser abordada aquí. Serán citados mediante el título común de la edición. Una síntesis de los mismos se halla en una breve introducción de al-Fārābī a la medicina, conocida como Risāla fi I-Tibb (ed. Plessner, 1973, pp. 310-312).

19 La expresión traduce poiētikē tekhnē (Plessner 1973, 309). La medicina produce salud del mismo modo que un artista una obra. Ibn Rushd usa el mismo concepto. En la edición juntina de Kulliyyāt, Colliget, $3 r$, șinā'a fāiila es "ars operativa" dado que el verbo fa'ala en árabe (hacer, actuar) permite esta posibilidad, que, además, concuerda con la idea del médico como artífice que se sigue de la definición de al-Fārābī, y el énfasis que éste y, en consecuencia, Ibn Rushd, ponen en las acciones realizadas con instrumentos destinadas a alcanzar los fines. La diferencia entre "operativa" y "productiva" no es trivial pero no puede ser analizada aquí.

20 Al-Fārābī, Radd, 38 i.f.-39:1; cf. la misma definición en Ibn Rushd, Kitāb al-Kulliyyāt fi l-țibb, 127:6-7.

21 Al-Fārābī, Radd, 41:9-42 i.f.; cf. además 53 i.f.-54:9.

22 Al-Fārābī, Radd, 38-40 y 43-50.

23 Al-Fārābī, Radd, 41:15-16 y 53:9

24 Al-Fārābī, Radd, 40:1-15 y 53:4-20. Cf. la trad. del primer texto en Forcada 2011a, 93.

25 Al-Fārābī, Burhān, 74:14-19

26 Al-Fārābī, Burhān, 74:18-19 y 23.

27 Al-Fārābī, Burhān, 72: 7-11.

28 Sobre esta conocida cuestión, cf. la revisión de Tuominen, 2007, pp. 96 ss.

29 Al-Fārābī, K. al-Musīqā al-kabīr, 101.

30 Black, pp. 2006, 34-35; además de la referencias indicadas, cf. al-Fārābī, Burhān, 74:3-9, donde el autor dice que las premisas obtenidas mediante la percepción de los sentidos o tomadas del conocimiento comúnmente admitido pueden ser el origen de deducciones que produzcan una certeza de segundo grado que, aunque inferior a la certeza aportada por la deducción apodíctica, pueden ser consideradas ciencia.

31 Al-Fārābī, Kitāb al-Milla, 57:1-19; trad. al inglés, Butterworth, 2001, pp. 104-105

32 Al-Fārābī, Milla, 57:19-58:6; cf. al-Fārābī, Ihșăa' al-'ulum, 104:3-9

33 Ibn Sīnā, Qānūn, kitāb 1, fann I, ta līm I, fașl 1, 3:13-14 (excepto indicación contraria, las siguientes citas del Qānūn proceden de la misma sección). Nótese que Ibn Sīnā dice que los términos naẓar, teoría, y 'ilm, ciencia, son sinónimos.

34 En este caso, Ibn Sīnā procede a una especie de sistematización taxonómica que ya hemos visto en al-Fārābī: las artes o las ciencias pueden ser prácticas, teóricas o compuestas; en este último caso, la teoría y la práctica deben estar interrelacionadas. La propuesta de lbn Sīnā para la medicina equivale a una disciplina compuesta.

35 Ibn Sīnā, Qānūn, 3:2-24; el ejemplo se pone es: hay tres tipos de fiebre, las complexiones son tres.

36 Ibn Sīnā, Risāla fĩ Aqsām al-'ulūm al-'aqliyya, 105.

37 Ibn Sīnā, Qānūn, vol. 1, pp. 4-5.

38 Ibn Sīnā, Qānūn, vol. 1. p. 3, líneas 25-29.

39 Ibn Sīnā, Qānūn, vol. 1, p. 3, líneas 24-25. Ibn Sīnā está pensando en una "práctica en potencia".

40 Ibn Sīnā, Qānūn, vol1. p. 3, líneas 29-30; literalmente, "aunque no hayas trabajado nunca".

41 Gutas, 2003, p. 152, habla de una teoría y una práctica aprendidas de forma "doxográfica".

42 Ibn Sīnā, Qānūn, 4:12 
43 Al-'Alawī, 1986, pp. 49-52: Ibn Rushd realiza su primer libro importante sobre lógica aristotélica, al-Darūrî fi l-manțiq, en el cual la influencia de al-Fārābī es muy evidente.

44 Ibn Rushd, Kulliyyāt, 128: 9-13 y 131:2-3.

45 Ibn Rushd, Kulliyyāt, 583: el manual general es K. alKulliyyāt; el manual especial, como Ibn Rushd se confiesa incapaz de hacerlo, es K. al-Taysīr de Abū Marwān Ibn Zuhr (m. 1162), el médico más importante de su generación y un destacado empírico (Kuhne, Álvarez Millán y García Sánchez, 2009).

46 Ibn Rushd, Sharh Urjūzat Ibn Sinā, 46:2-final y 48:16-22. La traducción tiene en cuenta: por una parte, las secciones directamente inspiradas en $K$. al-Burhān de al-Fārābī; por otra, las adiciones al texto árabe ya editado que presenta un manuscrito muy poco conocido del comentario de Ibn Rushd, conservado en la biblioteca de la Zāwiya Hamzawiyya de la comuna rural Zāwiyyat Sīdī Ḥamza (Marruecos). En el catálogo original de dicha biblioteca figuraba con el número 152 . El primer catálogo razonado asigna al manuscrito el número 194 (VV.AA, 2001, 1, p. 39), que utilizaremos en las líneas siguientes para designarlo. Este catálogo indica que la obra es de autor desconocido. En el catálogo más reciente de la biblioteca (Lahmar, 2009, p. 1206), su número es el 1890 . Este catálogo indica la posibilidad de que se trate del comentario de Ibn Țumlūs (m. 1223), discípulo de Ibn Rushd, pero no es cierto. Se trata de un manuscrito de fecha desconocida, anónimo, acéfalo y ápodo. Parece que faltan los folios primero y último. El texto conservado empieza en p. 46, I. 4, de la ed. de Coullaut Cordero, Fernández Vallina y Vázquez de Benito 2010 y termina en la p. 408, final. Consta de 95 folios de 16,5 por 20, $2 \mathrm{~cm}$, paginados del 1 al 190 . No parece haber lagunas en el cuerpo del texto, por lo que el manuscrito contiene la mayor parte del comentario de Ibn Rushd. Está escrito en letra magrebí clara, en tinta negra salvo los versos de Ibn Sīnā, en rojo. Incluyo, asimismo, algunos elementos de la traducción latina editada con el texto árabe que contribuyen a clarificar el sentido general del texto. La división en secciones es mía. Salvo una vez, no traduzco illm y sus derivados por "teoría" y palabras afines para respetar el espíritu del texto, que intenta transmitir a sus lectores la asociación entre medicina y ciencia, a pesar de su opinión profunda. La traducción no evita sistemáticamente las redundancias y repeticiones del texto árabe para transmitir mejor el espíritu del mismo. Modifico sustancialmente una primera versión parcial (Forcada, 2011a, pp. 107-109). Agradezco las atinadas sugerencias de Cristina Álvarez Millán y Abdallah Tagourramt sobre la interpretación del texto.

$47 \mathrm{Fi}$ 'l, en el sentido de "lo hecho", la obra que resulta de un arte productivo o șinā'a fã íla.

48 La frase recoge la descripción de las artes compuestas de al-Fārābī, Burhān, 74:16-19.

49 Fașl, predicable de la Isagoge de Porfirio, comentada por todos los grandes filósofos araboislámicos: es la diaphora, la diferencia que permite distinguir entre los elementos de un mismo género y es, en consecuencia, un elemento esencial de su definición.

50 Idea ya vista en Radd 'alā Jālīnūs de al-Fārābī: el médico conoce en función de sus fines; el filósofo natural debe alcanzar el máximo conocimiento teórico posible.
51 Cf. los dos versos siguientes, en los que Ibn Sīnā habla de los fundamentos de filosofía natural, enfermedades y síntomas.

52 Ad. ms. 194, 2:9: wa-kulli muwāfaqatin li-mā yaqūlū-hu Jālīnūs.

53 Ad. ms. 194, 2:11-12: wa-huwa ayḍan laysa bi-șahīhin lianna al-șanā'i'a al-'ilmiyya laysa mu'āqibu-hā allā yu'mala wa-l-juz'āni șinā'atun 'ilmiyyatun min fikrin wa-rawiyyatin. Ibn Rushd introduce la noción de arte estocástico. Aunque no se pueda descartar, es dudoso que la frase sea la interpolación de un copista: la frase se adapta bien al texto; el interpolador debería poseer unos conocimientos profundos de la obra de al-Fārābī e Ibn Rushd. Lo mismo se puede predicar de otras frases que veremos más adelante.

54 Pasaje muy parecido a al-Fārābī, Burhān, 59:1-7 y 74:21-23: la parte teórica de la medicina se orienta hacia la práctica; cf. $n$. v anterior.

55 Ad. ms. 194, 2:16: bi-l-ilm wa-l-amal; en la ed., 48:15, wa-l-amal, con menor sentido.

56 Aquí, al-'amal bi-l-yadayn y en § 3 siguiente al-'amal bi-lyad, "práctica con las dos mano/la mano", expresión que designa consistentemente a la cirugía (Ibn Sinnā, Urjūza, 188 ss., versos 1262 ss.).

57 "Imitación" aparece en la traducción debido al cambio de muhāāāt por muhāadhat, a pesar de que la primera palabra consta tanto en la ed. (48:16) como en el ms. 194. La segunda opción, que implica añadir solamente un punto a una letra, está de acuerdo con lo que dice el texto un poco más abajo citando a al-Fārābī.

58 Inicio de un largo texto parentético que presenta la medicina como ciencia.

59 Ad. según la trad. latina, 49:27: et aliam remotam ab eo.

60 En el texto árabe (48: 16, y ms. 194, 2: 19-29) se lee: a anna-hu yunzaru fi-hi al-iilmānī jamīan. La traducción latina reformula la frase en activa y con un sujeto y un locativo explícitos (cf. p. 49: 27-28): hoc est dictu quod Medicus speculetur in arte sua duas scientias insimul. No hay manera de saber si las adiciones figuraban en la fuente de la traducción latina o son una aclaración del traductor. Las dos palabras se pueden reintroducir en el texto árabe con un solo cambio en las consonantes de frase antes indicada ('ilmayni por 'ilmāni: a'nĩ anna [al-țabība] yanz̦uru fi-hi al-ilmānī jamīan.

61 Ad. ms. 194, 2 i.f.: wa-l-'ilmu al-thanī; consta en la trad. latina, 49:29.

62 Se refiere al 'ilm 'ilmī del Qānūn.

63 Ad. ms. 194, 3:2: dhakartu al-ilma al-țabíiyya 'ilmiyyan.

64 Ar. al-ilm.

65 Al-Fārābī, Burhān, 72:14-15: “[las ciencias] puramente teóricas son aquellas que, en todo aquello que abarcan, se circunscriben únicamente al conocimiento, que constituye su fin último".

66 Se refiere al 'ilm 'amalì del Qānūn. 
67 Pasaje que cita a al-Fārābī, Burhān, 72:19 y 73: 1-3. Los conocimientos prácticos de las disciplinas simples se aprenden mediante "la realización repetida de las acciones del arte", y mediante la "imitación" (ihtidhā'); en algunas artes, los conocimientos precisan de un cierto grado de elaboración y abstracción y son transmitidos mediante el ta'iimm bi-l-qawl, "la enseñanza mediante la palabra", es decir, mediante una explicación en cierto modo teórica. Este pasaje del Sharh también contiene los dos elementos esenciales de la descripción antes vista del médico perfecto de al-Fārābī en $K$. al-Milla.

68 Ad. ms. 194, 3: 6, recogida en la trad. latina, 51:2.

69 Ibn Abī Ușaybi'a, 'Uyūn al-anbā' fï țabaqāt al-ațibbā', 519.

70 Quizá pueda identificarse con un tratado mencionado por Ibn Abī Ușaybi'a, 'Uyūn, 566:6-7: Kitāb Tatabu' Masā'il Hunayn, "Libro del estudio de Masā'il de Hunayn".

\section{BIBLIOGRAFÍA}

Agnellus de Ravenna, (1982), Lectures on Galen De Sectis, (ed.) Westerink, Leendert G. [y miembros del Seminar Classics 609] Buffalo, Department of Classics-State University of New York at Buffalo.

Al-'Alawī, Jamāl al-Dīn (1986), al-Matn al-Rushdī. Madkhal liqirā'a jadīda, Casablanca, Dar Tūbqāl li-I-Nashr.

Álvarez de Morales, Camilo y Vázquez de Benito, Concepción (2001), "Apuntes y reflexiones en torno al Kulliyyāt de Averroes", en: Álvarez de Morales, Camilo (ed,), Ciencias de la Naturaleza en al-Andalus.Textos y Estudios. VI, Granada, Consejo Superior de Investigaciones Científicas, pp. 93-112.

Álvarez Millán, Cristina (2010), "The Case History in Medieval Islamic Literature: the Mujarrabāt and Tajrīb as Source", Medical History, 54, pp. 195-214.

Al-Fārābī, Ihṣāo' al-'ulum, ed. Amīn, 'Uthman (1949), Al-Fārābī. Ihșā' al-'Ulūm, El Cairo, Dār al-Fikr al-'Arabī.

Al-Fārābī, Kitāb al-Burhān, ed. Fakhry, Majid (1987), al-Manțiq 'inda al-Fārābī. Kitāb al-Burhān, wa-Kitāb Sharā'iț al-yaqīn ma'a ta'ālīa Ibn Bājja 'alā al-Burhān, Beirut, Dār al-Mashriq.

Al-Fārābī, Kitāb al-Jadal, ed. al-'Ajam, Rafīq (1986), al-Manțiq 'inda al-Fārābī. Al-juz' al-thālīt [vol.3]. Kitāb al-Jadal, Beirut, Dār al-Mashriq.

Al-Fārābī, Kitāb al-Khițāba, ed. Langhade, Jacques y Grinaschi, Mario (1971), Al-Fārābi, Deux ouvrages inédits sur la rhétorique, Beirut, Dar el-Machreq.

Al-Fārābī, Kitāb al-Milla, ed. Mahdī, Muḥsin (1991), Kitāb alMilla wa-nușūs ukhrā, Beirut, Dār al-Mashriq.

Al-Fārābī, Kitāb al-Musīqā al-Kabīr, ed. Khashaba, Ghațțās (s.a.), Kitāb al-Musīqā al-Kabīr, El Cairo, Dār al-Kātib al-'Arabī li-lTabā'a wa-I-Nashr.

Al-Fārābī, Risāla fï l-Radd 'alā Jālīnūs fi mā nāqāộa fï-hi Arisțūțalīs li-a'ḍā' al-insān, ed. Badawī, 'Abd al-Raḥmān (1980), Rasā'il falsafiyya li-I-Kindī wa-I-Farābī wa-Ibn Bājja
71 Ibn Ridwān, In Parvam Galeni artem commentatio, 175a177b, correspondientes a la introducción y primer tratado.

72 He omitido el párrafo sobre la crítica del estado neutro; cf. Ibn Rushd, Sharh, 46:2-8/trad. 424.

73 Ibn Ridwān, In Parvam Galeni artem commentatio, 176a C; cf. Ottosson, 1984, p. 71.

74 Se trata de un asunto hasta cierto punto polémico, sobre el cual Conrad, 1995, Fricaud, 1997, Forcada 2009 y Puig Montada, 2011.

75 Al-Marrākushī, al-Mu jijib fi talkhīs akhbār al-Maghrib, 175. 76 Ibn Rushd, Sharh, 44/trad. 423.

wa-Ibn 'Adī, s.I., Dār al-Andalus li-I-Ṭabā'a wa-I-Nashr wa-I-Tawzī'.

Al-Mājūsī (1877), Kāmil fi șina'at al-țibb, Būlāq (El Cairo), alMatba'a al-Amīriyya (2 vols).

Al-Marrākushī, al-Mu'jib fi talkhīs akhbār al-Maghrib, ed. AlHawwārī, Șalah al-Dīn (2006), al-Mu jib fi talkhīs akhbār al-Maghrib li-Abì Muhammad 'Abd al-Wāḥid ibn 'Alī alMarrākusī, Beirut-Sidón, al-Mahtaba al-'Așriya.

Al-Rāzī, Mudkhal ilā șināàt al-țibb, ed. Vázquez de Benito (1979), Libro de introducción al arte de la medicina o "Isagoge" de Abū Bakr Muhammad b. Zakarīyā al-Rāzī, Salamanca, Ediciones Universidad de Salamanca-Instituto HispanoÁrabe de Cultura.

Al-Rāzī, al-Manșūrī fī-l-țibb, ed. al-Șiddīqī, Hāzim al-B. (1987), al-Manșūrī fi-l-țibb li-Abī Bakr Muḥammad ibn Zakariyā alRāzī, Kuwait, Ma'had al-Makhțūț al-'Arabiyya-al-Munaẓz̧ama al-'Arabiyya li-l-Tarbiya wa-I-Thaqāfa.

Al-Ṭabarī, Firdaws al-ḥikma, ed. Siddiqi, M.Z. (1928), Firdausu'lHikmat or Paradise of Wisdom of 'Alí b. Rabban-al-Tabarī, Berlín, Sonnen-Druckerei G.M.B.H.

Al-Zahrāwī, Kitāb al-Tașrīf li-man 'ajiza 'an al-ta'līf, ed. Sezgin, Fuat (1986), "A presentation to Would-Be authors". On Medicine. Al-Tașrīf li-man 'ajiza ān al-ta'līf, Frankfurt, Frankfurt, Institut for the History of Arabic-Islamic Science (2 vols).

Arnaldez, Roger and Iskandar A.Z. (1975), "Ibn Rushd”, in: Charles C. Gillespie (ed.), Dictionary of Scientific Biographies, New York: Charles Scribner's Sons Publishers, 12, 1-9.

Autor desconocido, Jawāmi' al-Iskandarāniyyin/ Summaria Alexandrinorum, ed. Sezgin, Fuat (ed.) (2001), The Alexandrian Compendium of Galen's Work: Jawāmi' alIskandarāniyyin, Translated by Hunain ibn Ishāq. First Part, Frankfurt, Institut for the History of Arabic-Islamic Science.

Bar-Sela, Ariel y Hoff, Hebbel E. (1963), “Maimonides' Interpretation of the First Aphorism of Hippocrates", Bulletin of the History of Medicine, 37, pp. 347-354. 
Boudon Millot, Véronique (2003), “Art, science et conjecture chez Galien". En Barnes, Jonathan y Jouanna, Jacques (eds.), Galien et la philosophie, Ginebra, Vandoeuvres, pp. 269-298.

Bürgel, Johann Christoph (1967), “Averroes 'contra Galenum'. Das Kapitel von der Atmung im Colliget des Averroes als ein Zeugnis mittelalterlich-islamischer Kritik an Galen", $\mathrm{Na-}$ chrichten der Akademie der Wissenschaften in Göttingen. I. Philologisch-Historische Klasse, Göttingen, Vandenhoeck \& Ruprecht, pp. 263-340.

Butterworth, Charles E. (2001), Alfarabi. The Political Writings. Selected Aphorisms and Other Texts, Ithaca-Londres, Cornell U.P.

Chandelier, Joel (2010), "Medicine and Philosophy”, en: H. Lagerlund (ed.), Encyclopedia of Medieval Philosophy, HeideIberg, Springer (2 vols.), 1, pp. 745-752.

Conrad, Lawrence I. (1995), "An Andalusian Physician at the Court of the Muwahhịids: Some Notes on the Public Career of Ibn Tufayl," Al-Qanțara, 16, pp. 3-12.

El-Fekkak, Badr (2018), "Cosmic, Corporeal and Civil Regencies: al-Fārābī's anti-Galenic Defence of Hierarchical Cardiocentrism”, en: Adamson, Peter y Pormann, Peter E. (eds.), Philosophy and Medicine in the Formative Period of Islam, (Londres, Warburg Institute, pp. 255-268.

Endress, Gerhard, (1997), "L'Aristote arabe: réception, autorité et transformation du Premier Maître", Medioevo. Rivista di Storia della Filosofia Medievale, 23, pp. 1-42.

Fierro, Maribel (2009), "El saber enciclopédico en el mundo islámico". En Alvar Ezquerra Alfredo (ed.), Las enciclopedias en España antes de l'Encyclopédie, Madrid, Consejo Superior de Investigaciones Científicas, pp. 83-104.

Fierro, Maribel (2014), "The Islamic West in the Time of Maimonides: The Almohad Revolution". En Muehlethaler, Lukas (ed.), "Höre die Wahrheit, wer sie auch spricht": Stationen des Werks von Moses vom islamischen Spanien bis ins moderne Berlin, Göttingen, Vandenhoeck and Ruprecht, pp. 21-31

Ferre, Lola (2015), "Medicine through a Philosophical Lens: Treatise I of Isaac Israeli's Book on Fevers. Collins, Kenneth E.; Kottek, Samuel S.; Paavilainen, Helena M. (eds.), Isaac Israeli: the philosopher physician, Jerusalén: Muriel \& Philiip Berman Medical Library, pp. 111-132.

Forcada, Miquel (2009), "Ibn Ŷurŷ al-Dahabī, Aḥmad”. En Lirola, Jorge (ed.), Biblioteca de al-Andalus. 6, Almería, Fundación Ibn Țufayl, pp. 172-5

Forcada, Miquel (2011a), Ética e ideología de la ciencia: el médico filósofo en al-Andalus (siglos X-XII), Almería, Fundación Ibn Țufayl.

Forcada, Miquel (2011b), "Ibn Bājja on Medicine and Medical Experience", Arabic Sciences and Philosophy, 21, pp. 111148. https://doi.org/10.1017/S0957423910000147

Forcada, Miquel (2018), "Didactic poetry on medicine in late Al-Andalus and the Maghrib (12th-15th centuries)". En, Ibrahimi, Sidi Adil; Benjelloun, El Bachir; Laboudi, Fouad; Abdellah, Labiyad, Sbai, Abdennabi; Kabbaj, Kawtar (eds.),
IV International Congress of Fez on the history of Medicine in Muslim Heritage-VII Congress of the International Society of the Islamic Medicine. Congress Works, Fez, Sidi Mohamed Ben Abdellah University, pp. 168-178.

Forcada, Miquel (2019), "The Reception of Galen after Avicenna (Eleventh-Twelfth Centuries)". En Bouras-Vallianatos, Petros y Zipser, Barbara (eds.), Brill's Companion to the Reception of Galen, Leiden-Boston, Brill, pp. 227-241. https://doi.org/10.1163/9789004394353_014

Forcada, Miquel (2020), “Bronze and Gold. Al-Fārābī on Medicine", Oriens, 48, pp. 367-415. https://doi-org.sire.ub. edu/10.1163/18778372-04803003

Fortuna, Stefania (1987), "La definizione della medicina in Galeno", La Parola del Passato, 42, pp. 181-196.

Fricaud, Émile (1997), “Les Talaba dans la société almohade (le temps d"Averroës)", Al-Qanțara,18, pp. 331-88

Gätje, Helmut (1986), „Die Vorworte zum Colliget des Averroes", Zeitschrift der Deutschen Morgenländischen Gesellschaft, 136, pp. 402-427.

Garofalo, Ivan, (2007), "La Traduzione araba del De Sectis e il sommario degli alessandrini", Galeno, 1, pp. 191-210.

Gracia, Diego (1978), "The structure of medical knowledge in Aristotle's philosophy", Sudhoffs Archiv, 1978, 62, pp. 1-36.

Gutas, Dimitri (2003), "Medical Theory and Scientific Method in the Age of Avicenna", en: Reisman, David C. y al-Rahim, Ahmed H. (eds.), Before and After Avicenna: Proceedings of the First Conference of the Avicena Study Group, Leiden, Brill, pp. 145-62.

Gutas, Dimitri (2012), "The Empiricism of Avicenna”, Oriens, 40, pp. 391-436.

Hankinson, R.J. (2004), "Art and Experience: Greek Philosophy and the Status of Medicine", Quaestio, 4, pp. 3-24.

Haremska, Julia. (2009), "Ibn 'Abd al-Mu'min, Abū I-Rabí'”' in J. Lirola and J.M. Puerta Vílchez (eds.), Biblioteca de alAndalus. 2, Almería: Fundación Ibn Țufayl, pp. 602-4.

Ḥunayn ibn Isḥāq, Masā'il fïl-țibb, ed. Abū Rayyān, Muḥammad 'A.; 'Arab, Mursī; Mūsā, Jalāl M. (1978), Al-Masā'il fi l-țibb li-l-muta'allimīn, El Cairo-Beirut, Dār al-Kitāb al-Mișrī-Dār al-Kitāb al-Lubnānī.

Ḥunayn ibn Isḥāq [y Galeno], Kitāb Jālīnūs fi firaq al-țibb li-lmuta llimīn, ed. Salīm, Muḥamad S. (1977), Kitāb Jālīnūs fi firaq al-țibb li-l-muta'llimin naqala Abì Zayd ibn Ishāa al'Ibadī al-Mutațabbib, El Cairo, Maktabat Dār al-Kutub.

Ibn Abī Ușaybi'a, 'Uyūn al-anbā' fi țabaqāt al-ațțibā', ed. Riḍā, Nizār, Líbano, Dār Maktabat al-Ḥayāt.

Iohannes Alexandrinus, Commentaria in librum De sectis Galeni, ed. Pritchet, C.D. (1982), Iohannis Alexandrini Commentaria in librum de sectis Galeni, Leiden, Brill.

Ibn Ridwān, In Parvam Galeni artem commentatio. En Torrigiano, Pietro (1556), Plus quam commentum in Parvam Galeni artem, Venecia, Giunta.

Ibn Rushd (1553), Colliget, Auerrois Cordubensis Colliget libri VII, Venecia, Giunta. 
Ibn Rushd, Kitāb al-Kulliyyāt fī l-țibb, ed. al-Jābirī, Muhammad 'Ābid (dir.) (2008), al-Kulliyyāt fi l-țibb ma'a mu'jam bi-lmuștalahāt al-țibbiyya al-'arabiyya, Beirut, Markaz alDirasāt al-Waḥda al-'Arabiyya.

Ibn Rush, Sharh Urjūzat Ibn Sīnā, ed. Coullaut Cordero, Jaime; Fernández Vallina, Emiliano; Vázquez de Benito, María Concepción (2010), Averroes: Avicennae Cantica. Texto árabe, versión latina y traducción española, Salamanca: Ediciones Universidad de Salamanca.

Ibn Sīna (1877), al-Qānūn fï l-țibb, Būlāq (El Cairo), al-Matba'a al-Amīriyya (3 vols.).

Ibn Sīnā, Risāla fĩ Aqsām al-'ulūm al-'aqliyya. En Ibn Sīnā, Tis' rasā'il fi l-ḥikma wa-l-țabīiyyāt, El Cairo, Dār al-'Arab li-IBustānī, s.a.

Ibn Sīnā, Urjūza fi l-țibb, ed. al-Bābā, Muḥammad Zuhayr (1984), Min Mu'allafāt Ibn Sīnā al-țibbiyya, Alepo, Ma'had al-Turāth al-'Ilmī al-'Arabī

Jacquart, Danielle (1994), “Les antécédents gréco-latins de I'Isagoge Iohannitti". En Veázquez Buján, Manuel Enrique, Tradición e innovación de la medicina latina de la Antigüedad y de la Alta Edad Media: actas del IV Coloquio Internacional sobre los textos médicos latinos antigues, Santiago de Compostela, Universidade de Santiago de Compostela, 77-86.

Jacquart, Danielle (1998), “Medical Scholasticism”. En Grmek, Mirko D. (ed.), Western Medical Thought from Antiquity to the Middle Ages, Cambridge (Ma.), Harvard UP, 197-240.

Jacquart, Danielle (2002), “Lectures universitaires du Canon d'Avicenne". En Janssens, Julius y de Smet, Daniel (eds.), Avicenna and His Heritage, Lovaina: Leuven U.P., pp. 313-324.

Jacquart, Danielle (2003), “Avicenne et le galénisme”. En Garofalo, Ivan y Roselli, Amneris (eds.), Galenismo e medicina tardoantica. Fonti Greche, Latine e Arabe, Nápoles, Istituto Universitario Orientale, pp. 265-282.

Jacquart, Danielle (2013), "Anatomy, Physiology, and Medical Theory". En Lindberg, David C. y Shank, Michael H. (eds.), The Cambridge History of Science. Volume 2. Medieval Science, Nueva York, Cambridge University Press, pp- 590610. doi.org/10.1017/CHO9780511974007.027

Jacquart, Danielle; Palmieri, Nicoletta (1996) "La tradition alexandrine des Masa'il fi ț-țibb de Hunain ibn Ishāa". En Antonio Garzya (ed.), Storia e ecdotica dei testi medici greci, (Nápoles, M. D’Auria Editore, pp. 217-236.

Karimullah, Kamran I. (2017), “Avicenna and Galen, Philosophy and Medicine: Contextualising Discussions of Medical Experience in Medieval Islamic Physicians and Philosophers", Oriens, 45, pp. 105-149. https://doi.org/10.1017/ CHO9780511974007.027

Kuhne Bravant, Rosa; Álvarez de Millán, Cristina; García Sánchez, Expiración (2009), "Ibn Zuhr, Abū Marwān”. En Lirola, Jorge (ed.), Biblioteca de al-Andalus. 6, Almería, Fundación Ibn Țufayl, pp. 352-368

Laḥmar, Hamīd, (2009), Fahras wașfi li-makhțūțāt Khizānat alZāwiya al-Hamziyya al-'Ayyāshiyya bi-iqlīm al-Rashìdiyya, Rabat, Wizārat al-Awqāf wa-l-Shu'ūn al-Islāmiyya.
Lugt, van der, Maaike (2011), "Neither ill nor Healthy: the Intermediate State between Health and Disease in Medieval Medicine", Quaderni Storici, 136, 13-46.

Mc Ginnis, Jon (2003), "Scientific Methodologies in Medieval Islam", Journal of the History of Philosophy, 41, pp. 307-27.

Mc Ginnis, Jon, (2010), Avicenna, Oxford, Oxford U. P.

Mc Vaugh, Michael (1990), "The Nature and Limits of Medical Certitude at Early Fourteenth-Century Montpellier", Osiris, 6, pp. 62-84.

Ottosson, Per Gunnar (1984), Scholastic Medicine and Philosophy. A Study of Commentaries on Galen's Tegni (ca. 13001450), Nápoles, Bibliopolis.

Overwien, Oliver (2015), “Eine spätantik-alexandrinische Vorlesung über Galens De sectis in Ibn Hindūs Schlüssel zur Medizin (Miftāḥ al-țibb)“, Oriens, 43, pp. 293-337. https:// doi.org/10.1163/18778372-04303002

Pseudo-Galeno, Introductio sive medicus, ed. Petit, Caroline (2009), Galien. Le médecin. Introduction, París, Les Belles Lettres.

Plessner, Martin (1973), "Al-Fārābī's Introduction to the Study of Medicine". En Stern, Samuel M.; Hourani, Albert H.; Brown, Vivian (eds.), Islamic Philosophy and The Classical Tradition. Essays Presented by his Friends and Pupils to Richard Walzer on his Seventieth Birthday, Columbia (South Carolina), University of South Carolina Press, pp. ), 307-14.

Polansky, Ronald A. (2000), "Is Medicine Art, Science, or Practical Wisdom? Ancient and contemporary reflections". En Kuczewski, Mark G. y Polansky, Ronald A. (eds.), Bioethics: ancient themes in contemporary issues, Cambridge (MA), MIT Press, pp. 31-56.

Pormann, Peter A. (2003), "Jean le Grammairien et le De Sectis dans la littérature médicale d'Alexandrie". En Garofalo, Ivan y Roselli, Amneris (eds.), Galenismo e medicina tardoantica. Fonti Greche, Latine e Arabe, Nápoles, Istituto Universitario Orientale, pp.

Pormann, Peter A. (2004), "The Alexandrian Summary (Jawāmi') of Galen's On the sects for Beginners: Commentary or Abridgment?, Bulletin of the Institute of Classical Studies, 47, pp. 11-33.

Pormann, Peter A. (2013), “Avicenna on Medical Practice, Epistemology, and the Physiology of the Inner Senses", en: Interpreting Avicenna. Critical Essays, Adamson, Peter (ed.), Cambridge, Cambridge U.P, pp. 91-108. https://doi. org/10.1017/СВ09781139047890.006

Puig Montada, Josep (2011), "Ibn Rushd and the Almohad Context". En Fontaine, Resianne; Glasner, Ruth; Leicht, Reimund; Veltri, Giuseppe (eds.), Studies in the History of Culture and Science: a Tribute to Gad Freudenthal, Leiden, Brill, pp. 189-208. doi.org/10.1163/ ej.9789004191235.i-490.26

Richter-Benburg, Lutz (2008), "Abū Bakr al-Rāzī and al-Fārābī on Medicine and Authority. En Adamson, Peter, (ed.), In the Age of al-Fārābĩ: Arabic Philosophy in the Fourth/Tenth Century (Londres-Turín, The Warburg Institute, pp. 119-130. 
Strohmaier, Gotthard, (1998), "Reception and Traditions: Medicine in the Byzantine and Arab World". En Mirko D. Grmek (ed.), Western Medical Thought from Antiquity to the Middle Ages, Cambridge (Ma.), Harvard UP, pp. 139-69.

Stroumsa, Sarah (2009), Maimonides and his world. Portrait of a Mediterranean Thinker, Princeton-Oxford, Princeton U.P.

Temkin, Owsei (1935), "Studies on Late Alexandrian Medicine. 1. Alexandrian Commentaries on Galen's De sectis ad introducendos', Bulletin of the History of Medicine, 3, pp. 405430 [reimpreso en Temkin, Owsei, The Double Face of Janus and Other Essays in the History of Medicine, Baltimore, Johns Hopkins University Press, 1977, pp. 178-97].

Tuominen, Mira (2007), Apprehension and Argument. Ancient Theories of Starting Points for Knowledge, Dordrecht, Springer.
Van der Eijk, Philip J. (2005), Medicine and Philosophy in Classical Antiquity. Doctors and Philosophers on Nature, Soul, Health and Disease, Cambridge, Cambridge U.P.

Vegetti, Mario, (1994), "L'imagine del medico e lo statuto epistemologico della medicina", en: Hasse, Wolfgang (ed.), Aufstieg und Niedergang der Römischen Welt II 37.2, BerlínNueva York, pp. 1672-1717.

VV.AA. (2001), Dalīl makhțūțāt al-khizānāt al-ḥubusiyya, Rabat, Wizārat al-Awqāf wa-I-Shu'ūn al-Islāmiyya.

Zimmermann, Fritz W. (1976), „Al-Fārābi und die philosophische Kritik an Galen von Alexander zu Averroes". En A. Dietrich (ed.), Akten des VII Kongresses für Arabistik und Islamwissenschaft, Göttingen, Vandenhoeck \& Ruprecht, pp. 401-414.

Zimmermann, Fritz W. (1981), Al-Farabi's Commentary and Short Treatise on Aristotle's De Interpretatione, Londres, British Academy-Oxford University Press. 